\title{
Representações de profissionais de saúde sobre a morte e o processo de morrer
}

\author{
Representations of health professionals about death and the dying process
} Representaciones de profesionales de la salud sobre la muerte y el proceso de morir

\author{
Moema da Silva Borges', Nayara Mendes' \\ ' Universidade de Brasília, Faculdade de Ciências da Saúde, Departamento de Enfermagem. Brasília-DF, Brasil.
}

\section{Submissão: 24-11-2010 Aprovação: 26-03-2012}

\section{RESUMO}

Os currículos da área de saúde deixam uma lacuna na formação teórica e prática, permitindo que a morte seja interpretada como fracasso. A pesquisa objetivou apreender as representações sociais da morte e do processo de morrer para os profissionais de saúde. Trata-se de uma pesquisa qualitativa de natureza exploratória. Foram entrevistados cinco profissionais de saúde que prestam assistência a pacientes fora de possibilidades de cura. Utilizou-se o software Alceste para apreender o conteúdo das representações sociais dos entrevistados. Da análise de conteúdo das entrevistas emergiram dois eixos distintos: o primeiro eixo agrupa classes que dizem respeito à dimensão do profissional frente à morte; o segundo eixo refere-se à dimensão subjetiva frente à morte. Os resultados ressaltam a necessidade de investir na capacitação dos alunos não somente no desenvolvimento de habilidades técnicas, mas também no desenvolvimento de habilidades interpessoais, elementos fundamentais para o cuidado humano, sobretudo diante a morte.

Descritores: Esgotamento profissional; Tanatologia; Humanização da assistência; Educação em enfermagem.

\begin{abstract}
The curricula of the health area leave a gap in the theoretical and practical formation, allowing the interpretation of death as failure. This is a qualitative research of exploratory nature. The subjects were five health professionals who provide care to patients without cure possibilities. To analyze the data, it was used the software Alceste. From the analysis of the interviews two distinct axes had emerged: the first axis consists of classes that relate to the size of the professional front to death; the second axis refers to the subjective dimension in front of death. The results reveal the need to invest in the training of students not only in the development of technical skills, but also in the development of interpersonal skills, key elements in human care, especially on death.
\end{abstract}

Key words: Professional burnout; Thanatology; Humanization of assistance; Education, nursing.

\section{RESUMEN}

Los currículos del área dejan un vacío en la educación y formación, favoreciendo que la muerte sea interpretada como un fracaso. Lo objetivo es aprehender el significado de la muerte y el proceso de morir. Esta investigación cualitativa tiene carácter exploratorio. Los sujetos fueron cinco profesionales de la salud que prestan atención a los pacientes fuera de posibilidades terapéuticas. Para el análisis de datos, se utilizó el software Alceste, Del análisis del contenido de las entrevistas dos ejes distintos habían emergido: el primer eje agrupa las clases que dicen respecto a la dimensión del profesional frente a la muerte; al secundo eje dice respecto a la dimensión subjetiva ante la muerte. Los resultados subrayan la necesidad de investir en la formación de los estudiantes a desarrollar no sólo conocimientos técnicos sino, también, en el desarrollo de habilidades interpersonales, fundamentales para el cuidado humano, especialmente teniendo en cuenta la muerte.

Palabras clave: Agotamiento profesional; Tanatología; Humanización de la asistencia; Educación en enfermería. 


\section{INTRODUÇÃO}

As representações sociais sobre a morte e processo de morrer não resultam apenas da finitude biológica da vida, mas constituem um processo de interpretação socialmente construída e partilhada em diferentes contextos históricos, sociais e culturais ${ }^{(1)}$. Nesse sentido, assim como outros fenômenos da vida social, as distintas leituras sobre o processo da morte e do morrer têm determinado ao longo dos tempos diferentes interpretações e influenciado o modo de seu enfrentamento, bem como as formas de assistência ao moribundo.

$\mathrm{Na}$ idade média em geral o fim da vida acontecia de forma natural, com o moribundo cercado pelos entes queridos em seu leito. A morte domada ${ }^{(2)}$ era ritualizada, sagrada, comunitária e enfrentada com resignação. Existia espaço-tempo para a construção de "sistemas de defesa contra a angústia da separação, embasados em rituais de preparação para uma aceitação menos dolorosa, através de todo o processo de respostas humanas ao pesar até, por fim, ao luto"(3).

Fluindo na lógica da aceitação da ordem da natureza, na qual o ser humano se inseria na sociedade tradicional, a morte ocorria, sobretudo, devido às doenças infecciosas, marcadas por adoecimento e morte rápida. Os escassos meios de tratamento dessas doenças forçavam um convívio assíduo com a perda de um familiar ou membro próximo da comunidade (4). Nesse contexto, "a morte era vivenciada de modo mais familiar e onipresente, menos oculta, o que não significava que se tratasse de uma experiência tranquila, uma vez que os sentimentos religiosos de culpa e medo eram frequentes"(2).

Entretanto, o século XX testemunhou uma completa alteração na representação da morte. Nessa mudança será terminante o progresso técnico da medicina que possibilitou a diminuição das taxas de mortalidade. Uma medida efetiva será a "criação de uma política de saúde, preocupada com a proliferação das mortes e dos nascimentos, o nível de saúde e a duração da vida, fatores, que integram a longevidade humana aos interesses da economia e das racionalidades capitalistas"(5).

Assim sendo, as medidas de prevenção e controle social da saúde e da doença desempenharão um importante fator de afastamento da figura da morte na vida cotidiana e, consequentemente, na consciência individual. "A estrutura de personalidade dos indivíduos é alterada para o esvaziamento dos rituais seculares e um controle individual maior sobre a expressão dos sentimentos face ao sofrimento e a morte"(4).

Nessa perspectiva, a morte moderna ${ }^{(2)}$ será escondida, vergonhosa e negada; deslocada da ordem da natureza e, agora, administrada pelo saber e pela instituição médica. Nessa nova ordem social, o hospital passará a ser o lugar de eleição para articular intimamente os interesses do Estado com o contexto socioeconômico das políticas de saúde ${ }^{(5)}$.

Dessa forma, os argumentos médicos e de saúde pública deslocarão o moribundo de seu leito domiciliar para um leito no hospital. A inscrição da morte no espaço hospitalar a retirará da categoria do sagrado(4). A ideia da finitude buscará "fechar a angústia da morte dentro de um discurso e localizar o pensamento sobre ela em um lugar seguro dentro da sociedade (e fora de nós)"(6).
A transferência massiva dos moribundos para o hospital transformou-o no espaço social onde a morte se fará bastante presente e ele será "o terreno privilegiado para desenhar os modelos de socialização dos profissionais de saúde"(5). Entretanto, ao contrário do que se possa pensar, será no hospital que os profissionais serão preparados para o NÃO enfrentamento da morte.

Lá serão forjadas as estratégias para controlar as manifestações emocionais dos profissionais, pacientes e familiares, a fim de proteger a rotina institucional que precisará ser resguardada $^{(4)}$. A normatização estrita e hierarquização presentes na instituição hospitalar desenharão a pouca possibilidade de diálogo entre os diferentes atores sociais envolvidos no processo da morte e do morrer.

Nessa lógica, nos currículos da área de formação dos profissionais de saúde, a morte tem sido, no máximo, abordada pragmaticamente sob o ponto de vista científico, com enfoque nos sinais abióticos. A respeito do campo das emoções, das perturbações e mudanças que a possibilidade da morte acarreta pouco se fala(7).

Essa lacuna na formação teórica e prática, o investimento na preservação da vida a todo custo, a ideia de luta contra a morte e o enfoque na gratificação da cura(8) favorecerá que "na mente do profissional, a morte signifique colapso, falência, declínio e fracasso ${ }^{\prime \prime(8)}$. Esse sentimento de fracasso se transformará em fonte constante de angústia e constituirá um objeto fóbico, a morte será um tema tabu que deverá ser evitado(9).

Assim, estudos pioneiros sobre as práticas cotidianas da morte moderna ${ }^{(2)}$ em hospitais revelaram uma atitude defensiva da equipe institucional frente à morte ${ }^{(10)}$. De fato, ao aliar os interesses institucionais ao modelo de formação profissional, cria-se um modelo de negação da realidade que impede o sujeito/profissional de se defrontar com a inexorabilidade da finitude do paciente. Nesse modelo "a assistência em saúde é impessoal, mecânica e asséptica"(4).

Por volta dos anos 70 do século XX, a crítica aos excessos de poder da instituição médica, que desenvolveu uma assistência eminentemente racionalizada, super medicalizada que impede a autonomia do moribundo em consequência da submissão ao poder médico, começa a ser questionada ${ }^{(4)}$.

Indivíduos pertencentes a camadas sociais de visibilidade, com engajamento político, ideológico e social e atingido por AIDS serão, em parte, responsáveis pela criação de um movimento de reivindicação do direito de morrer com dignidade. Esse processo resultará na proposta de uma nova gestão do morrer, "na qual a relação de poder entre o enfermo, sua família e a equipe profissional seria transformada" (4).

Dessa forma, os cuidados paliativos, modelo da morte contemporânea, são herdeiros dos movimentos em prol da causa dos direitos civis; e do movimento New Age. O primeiro inseriu a reivindicação pelos direitos dos doentes, sua autonomia e mudança na relação de poder médico-paciente, enquanto o segundo incorporou na organização familiar e comportamento dos indivíduos novos hábitos, formas de consumo e comunicação. Os valores sociais passam a fazer parte de uma visão de mundo e práticas sociais ${ }^{(4)}$.

Entretanto, transcorridas quase quatro décadas das proposições de mudanças do modelo contemporâneo do morrer, 
observa-se que, durante seu processo formativo, o profissional de saúde, via de regra, não recebe informação e treinamento suficiente para acompanhar a morte e o processo de morrer. Assim, quando se verifica a falência dos meios habituais de tratamento e o doente se aproxima inexoravelmente da morte, raramente, os profissionais estão preparados para cuidar do seu sofrimento, bem como de sua família. Esse aspecto se reflete diretamente na qualidade da atenção prestada ao doente e sua família, sobretudo os que estão sem possibilidades de cura, ou seja, aqueles para quem a ciência não possui mais meios de deter a doença e o objetivo principal da assistência deixa de ser a cura e passa a ser o cuidado da pessoa.

Dessa forma, faz-se necessário conhecer como se forjaram as representações sociais dos profissionais de saúde acerca da morte, pois são elas que influenciam o modo de agir e reagir do profissional frente ao fenômeno e estão associadas a crenças e valores sociais do grupo profissional.

Diante do exposto, essa pesquisa teve como objetivo apreender as representações sociais sobre o processo da morte e do morrer para os profissionais de saúde que lidam com pacientes fora de possibilidades de cura.

\section{MÉTODO}

Trata-se de uma pesquisa de abordagem qualitativa de natureza exploratório-descritiva, baseado na fundamentação teórico-metodológica da abordagem do conteúdo das representações sociais. O campo de estudo foi um hospital-escola em Brasília e os sujeitos da pesquisa foram: uma nutricionista, duas enfermeiras e dois médicos, totalizando cinco profissionais de saúde. Para coleta de dados utilizaram-se dois instrumentos: 1) questionário de perguntas fechadas que objetivou identificar o perfil dos participantes; e 2) a técnica de entrevista guiada, com roteiro semiestruturado, com objetivo de apreender o conteúdo de suas representações sociais.

As entrevistas foram realizadas entre abril e maio de 2008. O critério de inclusão foi exercer atividades profissionais com pacientes fora de possibilidades de cura. Após a transcrição das entrevistas, os sujeitos tiveram acesso à leitura do manuscrito e puderam ratificar ou retificar as informações ali contidas e todos concordaram integralmente com o conteúdo transcrito. Para auxílio na análise do material verbal, utilizou-se o software Alceste (Análise lexical por contexto de um conjunto de segmentos do texto) $)^{(11)}$.

Esse software, ao analisar o corpus das entrevistas, permite, por meio de análises estatísticas, a identificação de categorias. Os resultados quantitativos possibilitam a interpretação qualitativa, a partir de traços típicos das categorias entre si, na sua relação com o objeto de estudo. Assim, buscou-se a identificação, no conteúdo das entrevistas, das classes/categorias que possibilitassem a apreensão do conjunto das representações sociais sobre a morte e do processo de morrer para os profissionais de saúde.

Obedecendo a legislação que regula à ética em pesquisa o protocolo foi submetido à apreciação do Comitê de Ética da Faculdade de Medicina da Universidade de Brasília, tendo sido aprovado sob o Parecer $n^{\circ}$. 006/2008. Os participantes do estudo, após concordarem em participar da pesquisa, assinaram o Termo de Consentimento Informado.

\section{RESULTADOS}

Os cinco profissionais entrevistados tinham idade entre 26 e 32 anos. Dois professavam a religião católica, um era espírita, um protestante e um luterano.

Após análise das entrevistas, foi possível apreender o conteúdo das representações sociais dos entrevistados. Emergiram dois eixos, compostos de cinco classes/categorias, apresentadas graficamente na forma de um dendograma (Figura 1).

Na Figura 1 observa-se que as representações dos entrevistados organizam-se em dois eixos. O primeiro eixo, composto pelas classes: 1 paliar?; 2 [sentimento de fracasso] e 4 [assistência tecnicista], remete à dimensão do profissional diante da morte e espelha um saber/fazer que traduz a filosofia do modelo biomédico, base da formação dos profissionais de saúde. O segundo eixo, composto pelas classes 3 [mecanismos de defesa] e crenças sobre a morte e o morrer, dá destaque à dimensão subjetiva diante da morte.

Para melhor compreensão da figura, esclarece-se que o dendograma representa as relações estatísticas, onde a força

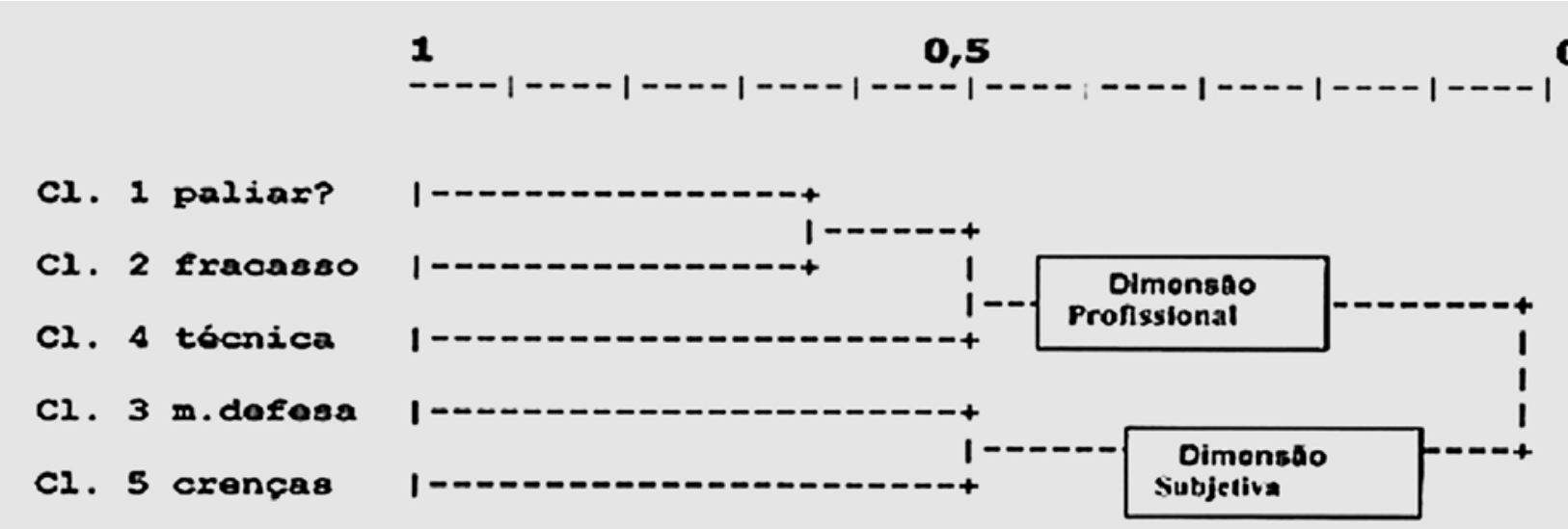

Figura 1 - Dendograma do corpus das representações sociais da morte e do morrer organizado em cinco classes. 
da relação entre as classes é expressa pela proximidade dos conteúdos das falas dos participantes. Assim, os valores acima de 0,5 dizem respeito às relações mais significativas e denominadas fortes, enquanto que as relações abaixo desse percentual são consideradas menos significativas e fracas. Desta forma, quanto mais próxima de 1, mais forte é a relação.

\section{DISCUSSÃO}

\section{Eixo 1: Dimensão Profissional Frente à Morte}

Nesse eixo, emergem os motivos que explicam a adoção da atitude defensiva perante a morte na prática profissional e confirma-se o tabu social da morte. Ganham destaque as consequências do enfoque fragmentado e tecnicista do modelo biomédico, que privilegia a atenção à doença e à cura em detrimento do cuidado ao enfermo.

Pode-se se deduzir, pela forte relação existente entre as classes 1 [paliar?] e a classe 2 [sentimento de fracasso], que o modelo curativo forja um tipo de saber/poder manifestado por uma assistência burocrática e uma linha de autoridade que desenha o mito do poder de salvar vidas. Não obstante, diante da morte, o profissional experimenta o sentimento de fracasso.

Observa-se ainda, que a relação $(0,5)$ existente entre a classe quatro (fig.1) e o conjunto composto pelas classes um e dois (fig.1), confirma que, para se proteger da angústia frente à morte, a prática cotidiana do profissional se ancora nas normas da instituição hospitalar e na assistência baseada na técnica.

Dessa forma, evidencia-se um processo de alimentação e retroalimentação de negação da morte. Nesse ciclo, as fases do poder/saber biomédico, muito embora não funcionem separadamente, não sejam redutíveis um ao outro, nem se definam por referência recíproca, fecundam-se mutuamente ${ }^{(5)}$.

A seguir, passaremos à discussão das classes que emergiram no eixo 1.

\section{Cuidados Paliativos?}

Quando questionados sobre o conhecimento do Programa Nacional de Assistência à Dor e Cuidados Paliativos ${ }^{(12)}$, os entrevistados demonstraram possuir limitado conhecimento sobre o tema.

Não saberia te dizer certinho do que trata, mas sei que ele fala de como a equipe deve agir com os pacientes nestas condições, fala do cuidado de forma humanizada, visando atender as necessidades do paciente. (P-5)

De maneiras de agir com pacientes com dor e câncer? Não sei. $(P-4)$

\section{Já. Só não sei direito do que trata, nunca li. (P-6)}

Na contramão da abordagem biologicista, a filosofia paliativista parte do princípio de que, se não for possível curar, sempre é possível cuidar. Assim, do silenciamento e da exclusão dos moribundos, o ideal paliativista confere voz e valoriza o desejo dos enfermos. Assim, no modelo de morte contemporânea o lema de ordem passa a ser a comunicação "se você pode, nem que seja por alguns minutos, sentar-se ao lado de seus pacientes e permitir-lhes falar sobre o que sentem, terá feito o bastante" ${ }^{\prime \prime 13)}$.

Nessa linha argumentativa, o principal objetivo da abordagem paliativa é propiciar uma melhor "qualidade de vida" para o doente e seus familiares. Os Cuidados Paliativos constituem uma modalidade terapêutica integrada e multidisciplinar e configura-se como uma tecnologia leve de alto impacto interpessoal que busca resgatar a humanização perdida nas modernas ações de saúde. Estudos sinalizam que o que mais importa aos pacientes são os elementos vivos da base do núcleo cuidativo, ou seja, ser acolhido com responsabilidade e verdadeiro vínculo de afeto ${ }^{(14)}$.

A partir do extrato da fala dos entrevistados, foi possível aprender que eles demandam por uma educação continuada que lhes permita prestar uma assistência mais humanizada.

Acredito que se ela fosse mais difundida a qualidade dos serviços prestados a esse tipo de paciente seria melhor. (P-3)

Sim, acho que deve mais difundida. Não digo nem pela mídia, mas dentro do próprio hospital. (P-6)

Está posto que o avanço da tecnologia médica de diagnósticos e tratamento cada dia mais sofisticados, não detém o adoecer, o envelhecer e o morrer. O prolongamento da vida em tempo não é garantia de qualidade. Assim, não se pode justificar a ausência da discussão da morte e do paradigma do cuidar na formação dos profissionais da saúde.

Nesse contexto, a filosofia paliativista favorece a oportunidade de amadurecimento profissional, dada pela consciência de sua limitação diante de uma enfermidade, estimula a adoção de atitudes compassivas de zelo e atenção que resultam em gratificação no cuidado ao moribundo e seus familiares, minimizando o sofrimento do profissional perante a morte ${ }^{(15)}$.

\section{O sentimento de fracasso}

Nessa classe, o discurso dos entrevistados ratifica que, no modelo de formação vigente, uma situação de morte em geral é interpretada como um teste à competência do profissional, fato gerador de sofrimento. A questão central é que o modelo biomédico ensina a tratar da doença e não a cuidar das pessoas, sendo assim, não abre espaço para que o aluno compreenda que o ser humano está geneticamente programado para morrer. É preciso fazer compreender que "fatores como a doença, acidentes, catástrofes, guerras etc., apenas aceleram a morte. Quando a atribuímos apenas a esses fatores negamos que a morte vem, em última instância, de dentro do ser humano"(16).

Além disso, a tradição da ética médica brasileira é focada em valores humanitários de tradição secular do respeito absoluto à vida. Entretanto, nesse universo secular, a própria morte e a dor muitas vezes são percebidas como sem sentido e, à medida que a vida escapa do controle médico, é interpretada como fracasso ${ }^{(17)}$. Essa concepção é estendida aos outros membros da equipe de saúde, uma vez que o modelo biomédico serve de base para a formação da área. 
A equipe ficou muito chateada e o cirurgião inconformado. Ele dizia: 'como isso aconteceu comigo?' Pela primeira vez na vida me senti uma impotente. Não sabia o que fazer o que dizer como ajudar. Fiquei em estado de choque e sem reação. Depois que levaram o corpo, tive de dar a notícia para a família, porque a equipe decidiu que eu era a mais capaz naquele momento. Foi péssimo!. (P-3)

Lembro que fiquei extremamente triste e com uma sensação de fracasso. Não havia nada que pudesse fazer. Putz, como foi ruim! Mesmo com todo conhecimento espírita, estava me sentindo um fracassado. Encarei da pior maneira possível e foi ruim para superar. $(P-2)$

Como fator agravante, observa-se que o mito do médico "sabe tudo" "salvador de vidas", não encontra ressonância na realidade da prática cotidiana. A diversidade das doenças e organismos humanos instaura um natural sentimento de insegurança sobre condutas e procedimentos a serem tomados. Por outro lado, o mito do salvador é reafirmado pela expectativa social, pois muitos pacientes têm medo de morrer, caso não obedeçam às ordens médicas ${ }^{(18)}$.

Outra questão importante, a ser levada em conta, quanto ao sentimento de fracasso na atual prática profissional diz respeito à alteração entre as fronteiras entre a morte e o morrer, propiciadas pelas técnicas de manutenção da vida. A partir delas, "a definição da morte revela-se circular, ligada à ação do médico, que tanto pode decidir interromper os cuidados como pode empreender esforços de reanimação. É, portanto, no mesmo momento em que se afirma um amplo poder médico, que surge a sua fragilidade ${ }^{(4)}$.

Dessa forma, a discussão sobre a finitude da vida humana é imprescindível para compreender os sentimentos, os anseios, os medos e inquietações dos aprendizes e profissionais. O estresse negativo crônico favorece o adoecimento e pode levar à Síndrome de Burnout. Essa síndrome, definida como a síndrome do esgotamento profissional, manifesta-se por três componentes: a exaustão emocional, a despersonalização e a falta de comprometimento com o trabalho ${ }^{(19)}$.

A exaustão emocional caracteriza-se pela redução dos níveis de energia para a realização de determinadas tarefas, ocorrendo um desgaste físico e ou psíquico. A despersonalização acarreta a perda de sensibilidade no trato consigo mesmo, colegas e pacientes. A falta de compromisso com o trabalho revela-se por um sentimento de inadequação pessoal e laboral, levando à perda da identidade profissional(19).

Diante desses aspectos, deduz-se que, na formação profissional, importam meios de ensinamentos que favoreçam a incorporação do desenvolvimento de habilidades cognitivas, afetivas e emocionais. O sofrimento da equipe não pode ser mascarado por uma atitude defensiva que se justifica pelo cumprimento de normas, técnicas e rotinas, que findam por resultar numa abordagem tecnicista da assistência e cuidado em saúde.

\section{A prática tecnicista}

Nessa classe o discurso dos entrevistados naturaliza o discurso racional da ciência, pautado no construto teórico-prático dos conhecimentos da anatomoclínica, da fisiopatologia e da genética médica, que compõem o universo do paradigma cientifico-tecnológico em saúde. Os profissionais validam esse tipo de saber/fazer/saúde como o melhor modo de produzir o cuidado em saúde a ser oferecido.

A lógica do modelo biomédico aplicado à formação propicia a criação de fatores que impedem a prática do cuidado, a saber: distanciamento dos interesses dos profissionais e dos pacientes; desconhecimento da importância das práticas de saúde de outros profissionais, o que dificulta o trabalho em equipe; e predomínio das modalidades de intervenção centradas nas tecnologias duras, a partir de um saber estruturado e reduzido à produção de procedimentos técnicos ${ }^{(16)}$.

Nesse enfoque, pode-se afirmar que a representação tecnicista do cuidado "não produz o Cuidado, ou seja, é necessário trazer para o momento do encontro entre profissional e usuários, o sentido existencial da experiência do adoecer e das práticas de saúde" ${ }^{(19)}$. A linha de autoridade imposta na relação corrobora que o ato de cuidar é sempre considerado secundário, quando comparado à técnica e ao procedimento.

O médico é um técnico, que deve ter sua postura ética e equilibrada, para passar a notícia de forma mais rápida e direta possível. Portanto, eu seria o mais franco e sincero possível, independente da reação deles. $(P-5)$

Como se sabe, o processo de formação tem dois momentos de aprendizagem: a teoria e a prática; "do ponto de vista técnico, o assunto morte, em geral, não é discutido na graduação e, no trabalho prático, ele é, quase sempre, desqualificado". ${ }^{(19)}$.

O discurso dos entrevistados não deixa dúvidas quanto à necessidade de uma preparação dos alunos para lidar com a morte

Na faculdade, nem gente morrer eu vi nos estágios. Não. As matérias não falavam de morte e os professores não conversavam com a gente sobre isso. (P-4)

Que eu me lembre, apenas nesses momentos. De jeito nenhum, até porque, como te falei, a gente nem fala nisso direito. $(P-6)$

Os entrevistados referiram que é no exercício da prática que eles se depararam com a morte, fato que interfere no diagnóstico, tratamento e gestão humanizada dos cuidados, criando um entrave no estabelecimento de uma relação efetiva entre profissionais, pacientes e familiares.

O que a gente aprende é na prática, encarando a perda de frente. $E$ eu ainda tenho dificuldades com isso. (P-6)

Vale ressaltar que a associação do modelo centrado na clínica curativa associado ao tabu social da morte, favorece a adoção da obstinação terapêutica ou abandono do paciente. Em ambos os casos, a morte social antecede a morte biológica, agravando o sofrimento de pacientes, familiares e profissionais. 


\section{Eixo 2: A Dimensão Subjetiva Frente à Morte}

Nesse eixo a força da relação existentes entre as classe 3 [mecanismos de defesa] e a classe 5 [crenças religiosas] corrobora que "comumente, o modo de enfrentamento da morte dependerá da interação entre as crenças religiosas introjetadas durante a vida do individuo e a intensidade e qualidade dos mecanismos projetivos utilizados" (16).

Aqui emergem as crenças, valores e significados dos entrevistados acerca do processo da morte e do morrer e as formas individuais de proteção frente à finitude.

\section{As crenças sobre a morte e o morrer}

Nessa classe comprova-se que as crenças acerca da morte e do processo de morrer guardam estreita relação com os dogmas religiosos dos entrevistados. Todas as religiões registram a crença da existência de vida após a morte. Duas fantasias coexistem nessa crença: a primeira diz respeito à existência de um mundo paradisíaco, regado pelo princípio do prazer e onde não existe sofrimento; a segunda faz referência a um mundo de sofrimento e lamentações traduzidas pela imagem do inferno.

Assim, "o axioma fundamental é que a morte não aniquila o ser humano; ela abre as portas para um além, para outra vida: inferno ou céu" (6). Pesquisa realizada sobre as vivências da enfermagem com a morte ratifica a "existência de vários elementos e concepções espirituais; alguns creem que o espírito fica vagando; outros, que a alma vai para um descanso, eterno, onde permanecerá para sempre" (20).

Sendo assim, as diferentes crenças parecem conduzir à mesma finalidade: "morte-passagem; morte-libertação; convívio-eterno-com-o-criador; ressurreição; reencarnação; morte fecunda...", ou seja, a crenças unificam-se na ideia de passagem de um mundo a outro ${ }^{(6)}$.

Na linha do imaginário social, para os sujeitos desse estudo, a morte foi representada como uma passagem para um lugar melhor.

Em minha concepção, morte não existe. Apenas perdemos o corpo físico, sendo que nosso espírito continua vivo, apenas em outro plano. Acredito que esta perda faz parte de nossas vidas. $(P-2)$

Penso que a morte é apenas o fim da vida. É o momento em que chegamos ao fim da linha, terminamos nossa missão na terra. É uma passagem para outro universo habitado por Deus. O processo começa no dia em que nascemos e termina no dia em que morremos. $(P-3)$

O extrato das falas corrobora ainda que, apesar da separação da filosofia religiosa do discurso laico da ciência, o elemento transcendente permanece vivo e permeia a existência do humano, como fundamento da vida, independente da escolaridade da pessoa.

Vejo o lado biológico que é a parada dos sistemas e a perda do que conhecemos como vida e o lado religioso que acredito ser quando vamos para um lugar melhor que a terra, ficando aqui apenas o corpo que não precisamos mais. $(P-4)$

Deduz-se que, do ponto de vista individual, a crença na transcendência humana parece construir um sentido para a morte, amenizando a dor e sofrimento da prática profissional a partir da própria consciência da morte.

\section{Mecanismos de defesa}

Teoricamente a morte pertence às chamadas categorias irrealizáveis, ou seja, categorias que incluem as experiências que não podemos antecipar e nem imaginar em nós mesmos ${ }^{(3)}$.

Então, a morte representa o nada e, para o ser humano pensante, a morte coloca a questão de que ele - o sujeito pensante - morre e se transforma em nada ${ }^{(6)}$. "Ora, se o nada é insuportável, a mente precisa usar estratégias para que esse sentimento insuportável deixe de o ser ${ }^{(18) "}$. Para esse fim são acionados diversos mecanismos de defesa, ou seja, artifícios mentais inconscientes utilizados para evitar que fatos, ideias, fantasias ou sentimentos penosos sejam vivenciados ${ }^{(18)}$.

Numa sociedade marcada pela busca do prazer imediato, a rapidez e o consumo, é previsível que a negação da dor, do sofrimento e da morte se integre. Essa ideia é asseverada na proposta de assepsia ambiental dos hospitais e se estende aos aspectos emocionais, propiciando a interdição da expressão dos sentimentos, para que não haja contágio emocional ${ }^{(4)}$.

Sendo assim, entre os entrevistados, verificou-se certa predominância do mecanismo de negação, embora a racionalização também se faça presente.

Foi possível inferir que os profissionais se protegem de uma maior vinculação com o moribundo. Mesmo frente à eminência de sua morte, articulam um discurso racional de que dispensam uma assistência desprovida de preconceitos.

Tenho que tratar como se fosse um paciente que tivesse em condições de recuperação, mas tenho de ter certeza que ele não ficará comigo muito tempo. Só assim para aceitar e entender. Trato ele como se fosse um paciente em condições de recuperação, não tem porque o atendimento ser diferente. $(P-1)$

A única coisa que faz diferença para mim é o fato de não ter muito que se fazer. Mas ali ainda existe um espírito, que merece ser cuidado e um corpo que também não pode ser menosprezado. $(P-2)$

Vale ainda, ressaltar, que a exclusão das emoções no processo formativo, por vezes, é transformada pela racionalização, numa técnica necessária para o efetivo desempenho profissional. Essa pretensa, neutralidade busca justificar o distanciamento interpessoal dos moribundos e seus familiares ${ }^{(18)}$.

Não trato mal, mas também não trato como os outros. Morro de medo de estar com ele e ele vir a óbito. Tento, então, ser rápida em meus procedimentos e evito conversar muito. $(P-3)$ 
Encaro como uma coisa normal; vou cuidar dele como qualquer outro já esperando que a qualquer hora ele possa morrer. $(P-4)$

É possível afirmar que o tabu social da morte, coligado ao modelo formativo, constitui uma barreira à prática de um cuidado humanizado. As representações acerca da transcendência da alma e a utilização dos mecanismos de defesa não constituem fator suficiente e eficaz para uma prática satisfatória.

\section{CONSIDERAÇÕES FINAIS}

Os resultados explicitam que as representações sociais sobre a morte e o processo de morrer são forjadas a partir do modelo de formação profissional e das referências individuais sobre o fenômeno da morte. O eixo da dimensão profissional evidenciou que, durante a graduação, os alunos são treinados para prevenir, curar e salvar vidas, naturalizando a assistência tecnicista como a única forma de "cuidado".

Ratificou-se que raramente, ao longo do curso, é criada a oportunidade de refletir sobre a perda dos pacientes e o impacto desse fato no processo de formação e na vida pessoal dos alunos. Como consequências, eles não são estimulados a identificar seus sentimentos e reações emocionais, bem como, os dos pacientes e familiares diante do processo de adoecimento e morte.

Dessa forma, a morte não assume sentido no fazer profissional, resultando numa prática eminentemente tecnicista que favorece o sentimento de fracasso e condições para a instalação de doenças ocupacionais. Ficou comprovado, ainda, que os esforços empreendidos na difusão de um novo modelo de gestão do morrer não alcançaram as condições necessárias para sua efetiva implementação como prática de cuidado.

Conclui-se pela necessidade de as instituições formadoras investirem na capacitação dos alunos visando à formação não apenas no desenvolvimento de habilidades técnicas assistências. É necessário aprender também a desenvolver as habilidades interpessoais de empatia, congruência, acolhimento e diálogo, elementos fundamentais para o cuidado humano, sobretudo diante a morte.

Para finalizar, fica o alerta de que é possível que a associação entre a lógica biomédica e os interesses institucionais, na sociedade capitalista, não favoreça apenas a perda do núcleo cuidativo do aprender/ fazer/saúde, mas da própria humanidade dos que a praticam.

\section{REFERÊNCIAS}

1. Moscovici S. Das representações coletivas às representações sociais: elementos para uma história. In: Jodelet D. As representações sociais. Rio de Janeiro: UERJ; 2001. p.18-66.

2. Ariès P. História da morte no ocidente. Rio de Janeiro: Ediouro; 2003.

3. Carvalho LS; Silva, Andrade, C; Santos, A C P O; Oliveira M A; P, Cabral, S.R; R, Costa, CM. Percepções de morte e morrer na ótica de acadêmicos de enfermagem. Online Braz J Nurs [periódico na internet]. 2006 [acesso em 17 jan 2009];5(3) Disponível em: http://www.uff.br/objnursing/index.php/nursing/article/view/507/116.

4. Menezes RA. Em busca da boa morte: antropologia dos cuidados paliativos. Rio de Janeiro: Garamond; 2004.

5. Carapinheiro,G. Saberes e Poderes no Hospital: uma sociologia dos serviços hospitalares. Porto: Afrontamento; 1998.

6. Rodrigues JC. Tabu da morte. 2.ed. Rio de Janeiro: Fiocruz; 2006

7. Kovàcs MJ. Os Profissionais de Saúde e Educação e a Morte. In: Kovàcs MJ, organizador. Educação para a morte: desafio na formação de profissionais de saúde e educação. São Paulo: Casa do Psicólogo; 2003.

8. Kubler-Ross E. Sobre a morte e o morrer. São Paulo: Martins Fontes; 1969.
9. Perazzo,S. O médico e a morte. Rev Psiquiátr Clín 1985;12(3-4):96-100.

10. Glaser,B; Strauss,A. Awarenes of Dying. Chicago: Aldine; 1965.

11. Brígido VC. ALCESTE: um programa informático de análise qualitativa de dados textuais. In: Moreira ASP, organizador. Perspectivas teórico-metodológicas em representações sociais. João Pessoa: Editora da UFPB; 2005. p.511-40.

12. Ministério da Saúde (Brasil) Programa Nacional de Assistência à Dor e Cuidados Paliativos. Portaria n. ${ }^{\circ}$ 19/GM, de 03 de janeiro de 2002. Institui a Câmara Técnica em Controle da Dor e Cuidados Paliativos. [Portaria na Internet]. Diário Oficial da União 13 dez 2006 [acesso 05 jul 2008]. Disponível em: http://www. dtr2001.saude.gov.br/ sas/PORTARIAS/Port2002/Gm/GM-19.htm.

13. Hennezel, M. A morte Íntima: Aqueles que vão morrer nos ensinam a viver. SÁ O, tradutora. São Paulo: Idéias e Letras; 2004.

14. Merhy EE. A perda da dimensão cuidadora na produção de saúde: uma discussão do modelo assistencial e da intervenção no seu modo de trabalhar a assistência. In: Campos CR, Malta DC, Reis AT, Santos A, Merhy EE. Sistema Único de Saúde em Belo Horizonte: reescrevendo o público. São Paulo: Xamã; 1998. p.103-20.

15. Quintana, A.M. Morte e formação médica: É possível a 
humanização? In: Santos FS, organizador. A arte de morrer: visões plurais. Volume 2. Bragança Paulista: Comenicus; 2009. p.37-47

16. Cassorla, RMS, A Negação da Morte. In: Incontri D, Santos FS, organizadores. A arte de morrer: visões plurais. Bragança Paulista: Comenicus; 2007. p.271-9.

17. Pessini, L. Distanásia; algumas reflexões bioéticas a partir da realidade brasileira. In: Franklin SS, organizador. Cuidados Paliativos: Discutindo a vida, a morte e o morrer. São Paulo: Atheneu; 2009. p.302-19
18. Schlienmanm A, L. Aprendendo a lidar com a morte no oficio do profissional de saúde. In: Franklin SS, organizador. Cuidados Paliativos: Discutindo a vida, a morte e o morrer. São Paulo: Atheneu; 2009. p.31-44

19. Ritter RS, Stumm EMF, Kircher RM. Análise de Burnout em profissionais de uma unidade de emergência de um hospital geral. Rev Eletrônica de Enferm 2009;11(2):236-48.

20. Salomé GM, Cavali A, Espósito VHC. Sala de emergência: o cotidiano das vivências com a morte e o morrer pelos profissionais de saúde. Rev Bras Enferm 2009;62(5):681-6. 